\title{
Covid-19: adverse mental health outcomes for healthcare workers
}

\author{
Work related stress can worsen existing conditions and crisis intervention might not suffice
}

\author{
Jessica A Gold assistant professor \\ Department of Psychiatry, Washington University in St Louis, St Louis, MO 63130-4899, USA
}

Frontline medical workers are at risk of not just adverse physical outcomes from coronavirus disease 2019 (covid-19) but psychological ones too. ${ }^{1}$ Data from previous pandemics, particularly after quarantine, suggest that healthcare workers might develop symptoms of post-traumatic stress disorder, depression, and substance use disorders. ${ }^{2}$ Preliminary data from China and Italy during the covid-19 pandemic offer further evidence; healthcare workers in China reported depression (in $50.3 \%)$, anxiety (44.6\%), and insomnia $(34.0 \%){ }^{34}$

Concerns about these data are compounded by high rates of pre-existing mental health and substance use disorders in this population, ${ }^{5}$ with physicians having rates of suicide among the highest of any profession. ${ }^{6}$ Although evidence based effective interventions and treatments are available, barriers such as stigma and lack of time limit their uptake, even in normal times. ${ }^{7-9}$ Less is known about interventions for the mental health of healthcare workers during pandemics.

In a linked study, Kisely and colleagues (doi:10.1136/bmj. $\mathrm{m} 1642$ ) report a rapid review and meta-analysis of qualitative, cohort, and cross sectional studies that examined the psychological reactions of healthcare staff working in any clinical setting during emerging virus outbreaks of severe acute respiratory syndrome (SARS), Middle East respiratory syndrome (MERS), H1N1 influenza, H7N9 influenza, Ebola virus disease, and covid-19. ${ }^{10}$ Using several databases, such as the Cochrane Central Register of Controlled Trials, PubMed, Embase, Psychifo, and medRxiv, the authors ended up with 282 potentially relevant full text papers that were assessed for eligibility. Ultimately 59 papers met the inclusion criteria. These studies looked at risk factors for stress and psychological distress and successful measures to manage them.

Personal caregiving and socioeconomic stressors, such as having children at home, an infected family member, and a lower household income were associated with adverse mental health outcomes..$^{10}$ The study confirms that psychosocial and workplace measures can improve employees' working lives and suggests that these, in turn, can improve mental wellbeing even though they are not explicitly mental health support services.

Interventions to ease caregiver or childcare burden or lessen financial stressors, such as hazard pay, although not mentioned in the paper, might mitigate negative mental health outcomes. Self-care is also critical given the benefits of diet, exercise, and sleep. ${ }^{11}$

Clear communication, access to adequate personal protective equipment (PPE), adequate rest, and both practical and psychological support were associated with better psychological outcomes. ${ }^{10}$

Concern about inadequate PPE during the covid-19 pandemic have focused on the risk of infection but, importantly, this study highlights the adverse effects that lack of PPE could have on mental health. ${ }^{12}$ Such institutional betrayal-when trusted and powerful institutions act in ways that can harm those dependent on them for safety and wellbeing-compounds trauma. ${ }^{13}$ To mitigate this, organizations should support staff voices and efforts to obtain PPE when possible.

Kisely and colleagues suggest that redeployment of staff to care for patients who are positive for covid-19 should be voluntary when possible. They did not, however, explore whether inability to communicate effectively with patients, bans on visitors, and barriers to the clinician-patient relationship were associated with poorer mental health among healthcare workers.

The authors suggest implementing psychological first aid (PFA) - a tailored psychological intervention based on the needs of individual staff to mitigate risk-rather than something such as debriefing, which has been found to be ineffective and in some cases to actually worsen post-traumatic stress disorder. ${ }^{1415}$ By not being compulsory, being more culturally sensitive, and focusing more on safety, comfort, and connection with social supports and resources, PFA can be a helpful intervention for the acute management of trauma. ${ }^{14} \mathrm{PFA}$ on the frontlines makes sense in the covid-19 pandemic, with its focus on less stigmatizing support and crisis intervention rather than counseling or psychiatric care. Yet focusing only on crisis intervention could miss those who need the care the most and could prevent long term responses from being put in place. We also need to be thinking about those with a history of psychiatric and substance use disorders who, not surprisingly, 
are predisposed to have worsening mental health during a pandemic. ${ }^{56}$ We want to identify the nurse who consumed alcohol before the pandemic and now is drinking a bottle a night to cope, or the doctor who was depressed before and coped by socializing but is now in isolation.

And long ignored, untreated, or undertreated depression plus covid-19 can be a deadly combination. Healthcare providers cannot make the mistake of minimizing these presentations as only crisis induced. They should screen, triage, and refer healthcare workers to the appropriate level and type of services before it is too late.

Competing interests: The BMJ has judged that there are no disqualifying financial ties to commercial companies. The author declares the following other interests: founding member and member of steering committee of TIME'S UP Healthcare (unpaid), advisory council member of Addiction Policy Forum, member of editorial board of MedPage Today and Psychiatric Times (unpaid), freelance writer for Conde Nast and Meredith, and sensitivity reader for Harper Collins. Provenance and peer review: Commissioned; not peer reviewed.

1 Adams JG, Walls RM. Supporting the Health Care Workforce During the COVID-19 Global Epidemic. JAMA 2020, published online 12 March. 10.1001/jama.2020.3972 32163102 2 Brooks SK, Webster RK, Smith LE, etal . The psychological impact of quarantine and how to reduce it: rapid review of the evidence. Lancet 2020;395:912-20. 10.1016/S0140-6736(20)30460-8 32112714

3 Lai J, Ma S, Wang Y, etal . Factors Associated With Mental Health Outcomes Among Health Care Workers Exposed to Coronavirus Disease 2019. JAMA Netw Open 2020;3:e203976.32202646
4 Rossi R, Socci V, Pacitti F, Di Lorenzo G, Di Marco A, Siracusano A, et al. Mental health outcomes among front and second line health workers associated with the COVID-19 pandemic in Italy. medRxiv 2020.04.16.20067801 [Preprint]. 2020.

5 Angres DH, McGovern MP, Shaw MF, Rawal P. Psychiatric comorbidity and physicians with substance use disorders: a comparison between the 1980s and 1990s. J Addict Dis 2003;22:79-87. 10.1300/J069v22n03_07 14621346

6 Kalmoe MC, Chapman MB, Gold JA, Giedinghagen AM. Physician Suicide: A Call to Action. Mo Med 2019:116.211-6.31527944

7 Melnyk BM, Kelly SA, Stephens J, etal . Interventions to Improve Mental Health, Well-Being, Physical Health, and Lifestyle Behaviors in Physicians and Nurses: A Systematic Review. Am J Health Promot 2020, published online 27 April. 10.1177/089011712092045132338522

8 DuPont RL, McLellan AT, White WL, Merlo LJ, Gold MS. Setting the standard for recovery: Physicians' Health Programs. J Subst Abuse Treat 2009;36:159-71. 10.1016/j.jsat.2008.01.004 19161896

9 Knaak S, Mantler E, Szeto A. Mental illness-related stigma in healthcare: Barriers to access and care and evidence-based solutions. Healthc Manage Forum 2017;30:111-6. 10.1177/0840470416679413 28929889

10 Kisely S, Warren N, McMahon L, Dalais C, Henry I, Siskind D. Occurrence, prevention, and management of the psychological effects of emerging virus outbreaks on healthcare workers: rapid review and meta-analysis. BMJ 2020;369:m1642.

11 Lopresti AL, Hood SD, Drummond PD. A review of lifestyle factors that contribute to important pathways associated with major depression: diet, sleep and exercise. J Affect Disord 2013;148:12-27. 10.1016/j.jad.2013.01.014 23415826

12 Godlee F. Protect our healthcare workers. BMJ 2020;369:m1324. 10.1136/bmj.m1324 32327409

13 Smith CP. Freyd JJ. Institutional betrayal. Am Psychol 2014:69:575-87. 10.1037/a0037564 25197837

14 Ruzek JI, Brymer MJ, Jacobs AK, Layne CM, Vernberg EM, Watson PJ. Psychological first aid. J Ment Health Couns 2007;29:17-4910.17744/mehc.29.1.5racqxjueafabgwp.

15 Rose S, Bisson J, Churchill R, Wessely S. Psychological debriefing for preventing post traumatic stress disorder (PTSD). Cochrane Database Syst Rev 2002;(2):CD000560.12076399

Published by the BMJ Publishing Group Limited. For permission to use (where not already granted under a licence) please go to http://group.bmj.com/group/rights-licensing/ permissions 